\title{
RESISTÊNCIA A COMPRESSÃO E ABSORÇÃO DE ÁGUA DE PEÇAS DE PISO INTERTRAVADO MANUFATURADAS COM RESÍDUOS DE PET
}

\author{
J. A. PASCHOALIN FILHO*, G. W. M. O. PIRES, L. V. S. REZENDE, J. C. C. SANTANA \\ Universidade Nove de Julho \\ paschoalinfilho@yahoo.com*
}

Artigo submetido em 22/11/2017 e aceito em 13/03/2019

DOI: 10.15628/holos.2019.6591

\section{RESUMO}

A construção é responsável por consumir grande parte dos recursos naturais não renováveis e gerar impactos ambientais significativos, que se iniciam na extração da matéria prima para a fabricação de materiais de construção e se estendem até o final do ciclo de vida das obras. Neste contexto, o desenvolvimento de materiais de construção mais sustentáveis se faz necessário como forma de mitigar os impactos ambientais causados e contribuir para o desenvolvimento sustentável do setor. Este trabalho traz o desenvolvimento de peças de concreto para pavimento intertravado, manufaturadas a partir da adição de resíduos de PET (Politereftalato de
Etileno) em substituição de parte dos agregados naturais. Para tal, foram realizados estudos de dosagem a fim de se determinar o traço para manufatura das peças. Em seguida, estas foram produzidas e ensaiadas de forma a verificar sua resistência a compressão e absorção de água. Ao final, foram estimados os custos de produção destas peças tendo como base a tabela SINAP 2015. Os resultados demonstraram que as peças desenvolvidas atenderam a requisitos estabelecidos por norma para sua utilização. No entanto, em relação aos custos, estas demonstraram-se pouco mais caras que peças convencionais.

PALAVRAS-CHAVE: Reciclagem, Pavimento Intertravado, Resíduos de PET

\section{COMPRESSIVE STRENGTH AND WATER ABSORPTION OF PRECAST CONCRETE BLOCKS FOR INTERLOCKING PAVEMENTS MANUFACTURED WITH ADDITION OF PET WASTES}

Civil Construction is responsible for consuming large amounts of the non-renewable natural resources and generating significant environmental impacts, which begin with the extraction of the raw material for construction materials manufacturing, and extend to the end of the life cycle of the buildings. In this context, the development of more sustainable building materials is necessary as a way to mitigate the environmental impacts caused and contribute to the sustainable development of the sector. This paper brings the development of concrete bricks for interlocking pavement, manufactured from the addition of PET
(Polyethylene Terephthalate) waste replacing part of the natural aggregates. For this, dosage studies were carried out in order to determine the dosage for bricks manufacturing. The bricks were produced and tested in order to verify their compression strenght and water absorption. At the end, the production costs of these bricks were estimated based on the SINAP 2015 table. The results showed that the developed bricks met the technical standard requirements for their use. However, in terms of costs, these have proved to be slightly more expensive than conventional parts.

KEYWORDS: Recycling, Interlocking Paves, PET wastes 


\section{INTRODUÇÃO}

A indústria da construção civil desempenha importante papel no desenvolvimento do país, pois contribui diretamente na redução dos déficits de infraestrutura e habitacional (Paschoalin Filho et al, 2016). No entanto, responde por um consumo considerável de recursos naturais, uma vez que grande parte das matérias primas necessárias para suas atividades são obtidas por meio de extração em jazidas e pedreiras. Além dos impactos causados pela extração, a construção civil também pode impor outras formas de agressão ao meio ambiente, tais como: poluição atmosférica e sonora, contaminação do solo, geração de resíduos, etc (Paschoalin Filho et al, 2016).

A crescente preocupação com as questões ambientais e a escassez de recursos naturais vêm aos poucos forçando indústria da construção a adotar novos conceitos e soluções técnicas que visam a sustentabilidade de suas operações. De acordo com Moreira et al (2012), nos últimos anos, a indústria da construção civil tem se preocupado em adotar a responsabilidade ambiental em suas atividades. Na visão de Gornisnki e Tonet (2016) o desenvolvimento de novos materiais de construção, que possuam maior resistência, durabilidade, menor impacto ambiental e maior ciclo de vida está se tornando uma exigência no mercado da construção civil.

Neste contexto, a reciclagem de resíduos sólidos gerados nas obras consiste em uma ferramenta de gestão alinhada ao conceito da sustentabilidade. A utilização de agregados reciclados, por exemplo, contribui na diminuição dos impactos da deposição de resíduos no meio ambiente e reduz a necessidade de matéria-prima natural.

A incorporação dos resíduos na fabricação de materiais de construção, como matéria-prima principal ou como adição, de forma a melhorar seu desempenho, é de grande importância (Safiuddin et al, 2010), pois além de garantir a correta destinação dos resíduos, proporciona uma alternativa sustentável para o setor da construção (Pappu et al, 2007).

A indústria da construção civil é capaz de reutilizar e reciclar diversos resíduos descartados por outros setores industriais. Na visão de Moreira et al (2012) resíduos de outros setores da indústria podem ser utilizados na manufatura de materiais de construção, substituindo matériasprimas naturais, total ou parcialmente.

Dentre os componentes da massa de resíduos sólidos urbanos (RSU), gerada todos os dias nos municípios brasileiros, embalagens PET podem ser destacadas (Paschoalin Filho et al, 2016). Saikia e Brito (2013) comentam que em Portugal, cerca de 10-14\% de todos os resíduos sólidos urbanos gerados consiste em materiais poliméricos. De acordo com Sulyman et al (2016) a massa de resíduos sólidos urbanos nos Estados Unidos é de 200.000 .000 de toneladas / ano, sendo 38\% em peso correspondente a produtos de papel, $8 \%$ em peso em materiais poliméricos e $3 \%$ em de peso em têxteis. Na Índia, segundo os autores, aproximadamente 40 milhões de toneladas de RSU são geradas anualmente; com um incremento de cerca de 2,0\% a cada ano. Neste cenário, os resíduos poliméricos constituem em torno de $12,3 \%$ em peso deste montante.

No Brasil, de acordo com a Associação Brasileira da Indústria do PET (ABIPET), no ano de 2007, 53,5\% deste polímero foi reciclado, ou seja, uma massa de 175.000 toneladas não recebeu qualquer tipo de reciclagem (Paschoalin Filho et al, 2016). 
O Politereftalato de Etileno (PET) pode ser usado como matéria-prima na manufatura de diferentes tipos de produtos devido ao seu baixo custo de produção e grande versatilidade. No entanto, a decomposição do PET é muito lenta, causando impactos ambientais consideráveis. Assim, a reciclagem de resíduos de PET na produção de novos materiais, como agregado em concreto e argamassa, poderia ser uma solução interessante para sua destinação, conferindo ao resíduo vantagens econômicas e ambientais (Saikia \& Brito, 2013).

Nos últimos anos, muitas pesquisas vêm sendo conduzidas em relação a utilização de plásticos reciclados em concretos e argamassas (Magalhães \& Fernandes, 2015). Muitos destes estudos relatam substituições totais ou parciais de agregados naturais por resíduos plásticos (em fibras ou triturados) em misturas de concreto e argamassa (Alfahdawi et al, 2016).

Saikia e Brito (2014) estudaram a adição de resíduos de PET na fabricação de concreto. Esta pesquisa consistiu na substituição de $5 \%, 10 \%$ e $15 \%$ do volume de agregados naturais por três diferentes granulometrias de PET na dosagem do concreto. Na mesma linha, Akçaözoğlu et al (2010), sugerem a utilização do resíduo triturado de garrafas PET na dosagem de concreto em substituição a agregados naturais. Duarte (2013), demonstrou a viabilidade técnica da utilização de resíduos de construção e PET na obtenção de argamassa, também em substituição a agregados naturais. Modro et al (2009), estudaram a influência da adição do resíduo de PET no concreto de cimento Portland. Para isto escolheram substituir parte do agregado natural por resíduo nas proporções, em volume, de 10\%, 20\%, 30\%, 40\%. Marzouk et al (2007) utilizaram resíduos granulares de PET como agregados na manufatura de concretos leves. Os autores concluíram que garrafas PET moídas em pequenos grãos podem ser utilizadas com sucesso na substituição de agregados naturais no concreto. Ramadevi e Manju (2009) estudaram a substituição de areia em volumes de $0,5 \%, 1 \%, 2 \%, 4 \%$ e $6 \%$ por resíduos de garrafas PET em fibras. Baseados nos experimentos conduzidos, os autores concluíram que: a) a resistência a compressão sofreu incremento até $2 \%$ de substituição e decresceu gradualmente para porcentagens de 4 e $6 \%$, b) a resistência a flexão apresentou crescimento até $2 \%$ de substituição de PET e decresceu gradualmente a partir de $4 \%$.

Sulyman et al (2016) comentam a respeito da utilização de adição de fibras de PET reciclado no concreto. De acordo com os autores, além da melhor destinação destes resíduos e da valoração destes, a incorporação confere ao concreto características como: redução do peso específico e custo mais baixo em relação a utilização de fibras convencionais (aço, vidro, carbono, polipropileno, etc). Segundo os autores a utilização de resíduos moídos de garrafas PET como agregados na dosagem de concretos e argamassas, além de proporcionar vantagens técnicas consideráveis, promove benefícios no descarte destes resíduos e reduz a poluição ambiental.

Wilinski et al (2016) destacam a utilização de resíduos de PET como fibras para reforço de concreto, prevenindo fissuras de retração. No entanto, os autores destacam que fibras poliméricas, tal como PET, podem apresentar problemas de adesão na pasta de cimento. Ochi et al (2007) determinaram que fibras de PET sob forma de fios, com diâmetro de $700 \mu \mathrm{m}$ e $30 \mathrm{~mm}$ de comprimento, quando adicionadas em proporções de1,5\% do volume do concreto, causam um incremento na resistência a flexão em torno de $30 \%$ e um incremento na resistência a compressão de $10 \%$. Fibras com diâmetros inferiores a $700 \mu \mathrm{m}$ não influenciam as características mecânica do concreto de forma tão favorável. 
Fioriti et al (2007) comentam que a utilização de pavimentos intertravados com peças prémoldadas de concreto vem crescendo em todo o mundo. Devido a suas características de engenharia favoráveis e facilidade executiva, peças para pavimento intertravado têm sido estudadas pelo meio técnico e científico. Dentre as pesquisas conduzidas destacam-se aquelas que propõem a incorporação de diversos tipos de resíduos na dosagem de concretos para manufatura destas, tais como: borracha de pneu, PET, mármore, resíduos de construção, fibras naturais (Fioriti et al, 2007; Fioriti et al, 2010; Pires, 2015; Gencel, 2012; Thanaya, 2009; Navya; Rao, 2014).

Nesse contexto, este trabalho traz o desenvolvimento e a avaliação de peças intertravadas de concreto, manufaturadas com adição de resíduos de PET (Politereftalato de Etileno) em flocos; no intuito de se propor uma forma alternativa para a destinação destes resíduos. Os parâmetros obtidos foram comparados aos requisitos apresentados na ABNT NBR 9781:2013 a fim de atestar a conformidade técnica das peças produzidas. Ao final, realizou-se a composição dos custos de manufatura destes com base na tabela SINAP 2015. Dessa forma, este trabalho tem como objetivo demonstrar a viabilidade técnica e os custos de manufatura de um material de construção obtido a partir da incorporação de resíduos poliméricos, bem como ressaltar a necessidade da inserção da variável ambiental no setor da construção, como forma de mitigar os impactos gerados pelas suas atividades cotidianas.

A seguir, são apresentados os procedimentos metodológicos utilizados nesta pesquisa.

\section{METODOLOGIA}

\subsection{Coleta de materiais}

Para o desenvolvimento deste trabalho foi necessária a escolha de materiais com características específicas, como o tipo de cimento, granulometria dos agregados e resíduo de PET e o tipo de aditivo utilizado na dosagem. Os materiais foram escolhidos baseados em critérios normalmente utilizados na confecção do concreto, sendo estes: Cimento Portland com Alta Resistência Inicial (CPV - ARI PLUS), agregado natural graúdo nas dimensões brita \#0 e \#1, agregado miúdo e aditivos plastificante e superplastificante.

A amostra de PET foi coletada em uma usina de reciclagem localizada no município de Mauá. Este material foi produzido por meio de moagem, em moinho de martelo, de garrafas PET de diversas colorações, sem tampa, rótulo e contaminação.

A coleta das amostras de agregados naturais atendeu as recomendações da ABNT NBR NM 26:2009 - "Agregados - Amostragem", que estabelece os procedimentos para a correta coleta, armazenagem e transporte das amostras de agregados naturais graúdos e miúdos para concreto destinados a ensaios em laboratório.

A amostra de cimento foi coletada, armazenada e transportada obedecendo os critérios estabelecidos na ABNT NBR 5741:1993 - “Extração e Preparação de Amostras de Cimento". Para a amostragem do PET em flocos, também foi utilizada a ABNT NBR NM 26:2009 - "AgregadosAmostragem". 


\subsection{Caracterização dos materiais utilizados}

Para a verificação dos parâmetros físicos dos agregados em ralação às suas dimensões, densidade e nível de impurezas, foram conduzidos ensaios laboratoriais para confrontar as amostras coletadas com as especificações técnicas da ABNT NBR 7211:2009 "Agregados para concretos - Especificação", que apresenta os requisitos exigíveis em relação aos agregados miúdos e graúdos destinados à produção de concretos de cimento Portland.

Os resíduos de Politereftalato de Etileno (PET) foram caracterizados quanto à dimensão dos grãos de acordo com a ABNT NBR NM 248:2003 “Agregados - Determinação da composição granulométrica", tendo em vista o objetivo do trabalho, ou seja, a substituição de parte dos agregados naturais pelos resíduos de PET.

Foram conduzidos ensaios de caracterização do cimento Portland atendendo às especificações da ABNT NBR 5733:1991 “Cimento Portland de Alta Resistência Inicial”. Foi utilizado aditivo superplastificante à base de ácido carboxílico, associado a um aditivo plastificante multifuncional de acordo com as especificações do fabricante.

\subsection{Estudo de dosagem}

Foram realizados estudos de dosagem do concreto. Para tal, levou-se em consideração a necessidade de trabalhabilidade da mistura, verificada pela sua consistência por meio do ensaio de abatimento do tronco cone e a necessidade de atingir resistência característica à compressão fpk >35MPa aos 28 dias de cura e absorção de água menor ou igual a $6 \%$, conforme especificado pela ABNT NBR 9781:2013 “Peças de concreto para pavimentação - Especificação e métodos de ensaio" (itens 5.4 e 5.5 ).

No estudo de dosagem foi utilizado o método da Associação Brasileira de Cimento Portland $(A B C P)$ adaptado do método American Concrete Institute ( $A C l$ ) (Rodrigues, 1995). Este método foi escolhido por ser utilizado na obtenção de concretos de consistência plástica à fluída e por fornecer uma primeira aproximação da quantidade dos materiais necessários na realização da mistura experimental. $O$ método de dosagem é baseado nas características dos materiais constituintes do traço de concreto e na quantidade de água, além da finalidade do uso do próprio concreto.

A fixação do traço inicial de referência (traço 1) sem a adição de resíduos de PET, ocorreu fixando-se os teores de argamassa e água de acordo com a trabalhabilidade e resistência de dosagem ( $\mathrm{fcj}$ ) requeridas para a confecção das peças intertravadas. A resistência de dosagem (fcj) foi estabelecida de acordo com a equação 1 conforme a ABNT NBR 9781:2013.

$$
f c j=f c k+1,65 \times s d
$$

Onde:

$\mathrm{fcj}=$ resistência característica a compressão do concreto na idade "j" dias (MPa);

$\mathrm{fck}=$ resistência característica do concreto a compressão (MPa);

sd= desvio padrão. 
De acordo com o objetivo de substituir no concreto parte de agregado natural, foi definida a substituição simultânea e em frações equivalentes, de uma parte do agregado natural graúdo e de uma parte do agregado natural miúdo, por resíduos de PET em flocos. Seguindo esta premissa, foram dosados traços de concreto, nos quais parte dos agregados naturais foram substituídos, em volume, nas proporções definidas em: 2,5\%, 5,5\%, 9,5\%, 15\%, 22\% e $36 \%$.

Para encontrar o traço que garantisse simultaneamente a maior proporção de resíduo e resistência compressão, foi determinada uma correlação linear entre porcentagens de PET utilizadas com os valores de resistência a compressão de corpos de prova rompidos aos 28 dias de tempo de cura.

2.4 Moldagem e armazenamento dos corpos de prova e das peças

O formato utilizado na manufatura das peças foi o Tipo I conforme item 5.1.1 da ABNT NBR 9781:2013. As Figuras 1 e 2 apresentam as dimensões das peças produzidas.

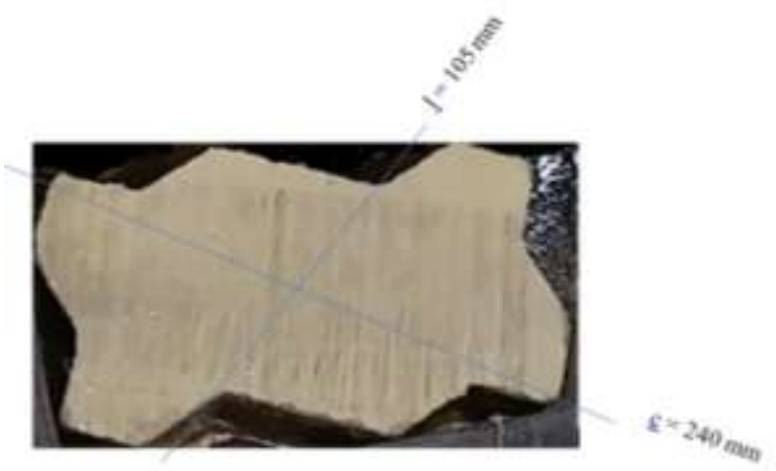

Figura 1: Vista superior da peça. Fonte: Dados da Pesquisa.

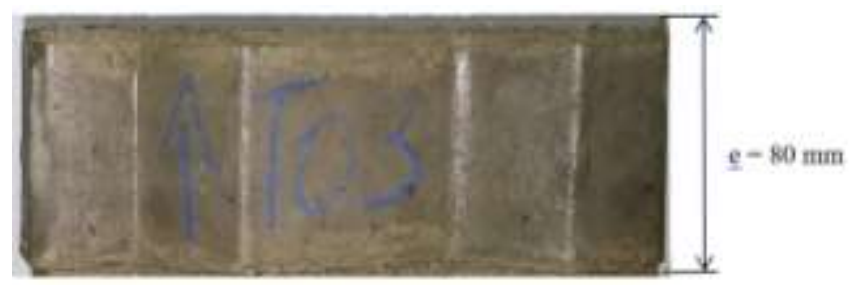

Figura 2: Vista lateral da peça. Fonte: Dados da Pesquisa.

A cura dos corpos de prova e das peças foi realizada em câmara úmida com umidade e temperaturas controladas, atendendo aos requisitos da ABNT NBR 9479:2006 "Argamassa e concreto - Câmaras úmidas e tanques para cura de corpos-de-prova", com umidade acima de 95\% e temperatura de $25 \pm 2^{\circ} \mathrm{C}$. Os tempos de cura foram 7 e 28 dias.

\subsection{Ensaios de resistência a compressão e absorção de água}

Para avaliação da resistência a compressão dos corpos de prova e das peças, manufaturados nos traços em estudo, foram conduzidos ensaios de resistência a compressão 
conforme especificações da ABNT NBR 9781:2013 - "Peças de concreto para pavimentação Especificação e método de ensaio".

Para avaliação das peças, com tempo de cura de 28 dias, foram realizados ensaios de absorção de água, tal como recomendado pela ABNT NBR 9781:2013 - "Peças de concreto para pavimentação - Especificação e método de ensaio". Para o cálculo da absorção de água foi utilizada a seguinte equação:

$$
A=\frac{m 2-m 1}{m 1} \times 100(2)
$$

Onde

$A=$ Absorção de cada bloco, expresso em porcentagem (\%)

$m 1=$ Massa do bloco seco, expresso em gramas (g)

$m 2$ =Massa do bloco saturado, expresso em gramas $(\mathrm{g})$

\section{RESULTADOS E DISCUSSÕES}

\subsection{Caracterização dos materiais utilizados}

No Quadro 1 são apresentados os resultados dos ensaios conduzidos a fim de se avaliar o aglomerante utilizado na composição dos traços. Todos os resultados atenderam aos parâmetros exigidos em relação ao recebimento do cimento Portland de Alta Resistência Inicial (CPV - ARI).

Quadro 1. Características físicas obtidas para as amostras de cimento (ABNT NBR 5733:1991)

\begin{tabular}{|c|c|c|c|c|}
\hline Idade (dias) & Tensão (MPa) & $\begin{array}{c}\text { Tensão Média } \\
\text { (MPa) }\end{array}$ & $\begin{array}{l}\text { Parâmetro de } \\
\text { norma (MPa) }\end{array}$ & $\begin{array}{c}\text { DRM - Desvio relativo máximo } \\
(\%)\end{array}$ \\
\hline \multirow{4}{*}{1} & 20,6 & \multirow{4}{*}{20,6} & \multirow{4}{*}{$\geq 14$} & \multirow{4}{*}{0,50} \\
\hline & 20,7 & & & \\
\hline & 20,6 & & & \\
\hline & 20,6 & & & \\
\hline \multirow{4}{*}{3} & 39,9 & \multirow{4}{*}{38,8} & \multirow{4}{*}{$\geq 24$} & \multirow{4}{*}{2,8} \\
\hline & 38,4 & & & \\
\hline & 38,3 & & & \\
\hline & 38,6 & & & \\
\hline \multirow{4}{*}{7} & 41,3 & \multirow{4}{*}{40,9} & \multirow{4}{*}{$\geq 34$} & \multirow{4}{*}{1,0} \\
\hline & 40,6 & & & \\
\hline & --- & & & \\
\hline & 40,7 & & & \\
\hline Área específica & \multicolumn{4}{|c|}{$4626,00 \mathrm{~cm}^{2} / \mathrm{g}$} \\
\hline Finura \#0,075 & \multicolumn{4}{|c|}{$0,16 \%$} \\
\hline Massa específica & \multicolumn{4}{|c|}{$3,06 \mathrm{~g} / \mathrm{cm}^{3}$} \\
\hline \multicolumn{5}{|c|}{ Tempos de início e fim de pega } \\
\hline \multicolumn{2}{|l|}{ Tempo } & \multicolumn{2}{|c|}{\begin{tabular}{|l|l} 
Valor obtido & \\
\end{tabular}} & Parâmetro de norma \\
\hline \multicolumn{2}{|l|}{ início } & \multicolumn{2}{|l|}{ 3:00h } & Mínimo: $1 \mathrm{~h}$ \\
\hline fim & & \multicolumn{2}{|l|}{$4: 30 h$} & Máximo: 10h \\
\hline
\end{tabular}

Fonte: Dados da Pesquisa 
A Figura 3 apresenta as curvas de distribuição granulométrica dos agregados miúdos e graúdos, bem como do PET, utilizados nas dosagens experimentais.

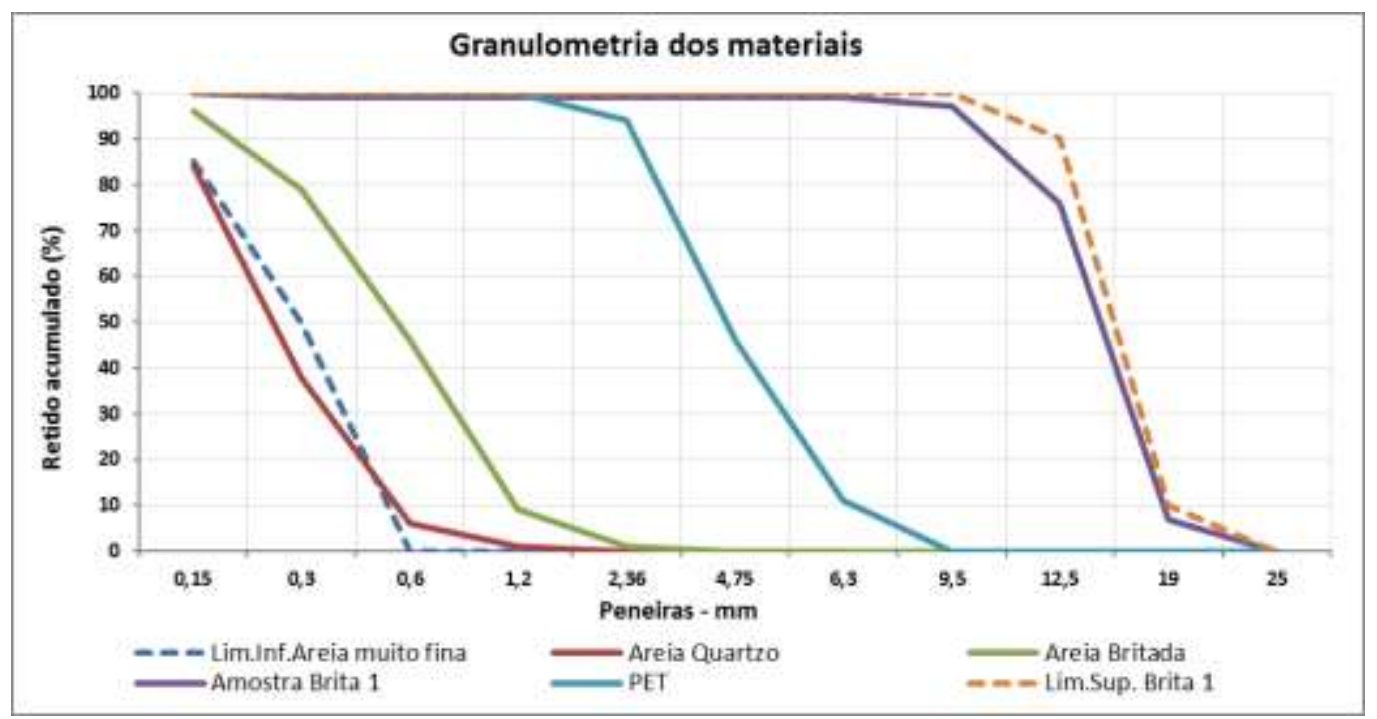

Figura 3. Curva granulométrica dos agregados e resíduos de PET (ABNT NBR NM 248:2003). Fonte: Dados da Pesquisa

As curvas granulométricas apresentadas na Figura 3 demonstram o enquadramento dos agregados dentro do limite superior da brita \#1 e inferior ao da areia muito fina. Pode-se observar que resíduos de PET se enquadram no meio das faixas mínimas e máximas. A determinação da massa unitária em estado solto, teor de argila em torrões e materiais friáveis, determinação do teor de partículas finas passantes na peneira $75 \mu \mathrm{m}$, teor de impurezas orgânicas, massa específica e absorção, obtidos para os agregados, são apresentados no Quadro 2.

Quadro 2. Ensaios físicos conduzidos nos agregados naturais

\begin{tabular}{|l|c|c|c|}
\hline \multicolumn{1}{|c|}{ Ensaios } & Brita\#1 & Areia natural & Areia artificial \\
\hline Massa unitária - Estado solto $\left(\mathrm{kg} / \mathrm{m}^{3}\right)$ & 1379 & 1504 & 1336 \\
\hline $\begin{array}{l}\text { Teor de argila em torrões e materiais } \\
\text { friáveis (\%) }\end{array}$ & 0 & 0,01 & 0,22 \\
\hline $\begin{array}{l}\text { Material fino passante na peneira } \\
\mu \mathrm{m} 75(\%)\end{array}$ & 0,6 & 2,0 & 2,0 \\
\hline Impurezas orgânicas húmicas (ppm) & ----- & Mais clara & Mais clara \\
\hline Massa específica (g/cm $\left.{ }^{3}\right)$ & 2,68 & 2,66 & 2,67 \\
\hline Absorção de água (\%) & 0,9 & 0,8 & 1,4 \\
\hline
\end{tabular}

Fonte: Dados da Pesquisa

Os resultados apresentados no Quadro 2 demonstram que os agregados utilizados na confecção dos traços atendem aos descritos na ABNT NBR 7211:2009 - "Agregados para concreto - Especificação", a qual especifica os requisitos exigíveis para recepção e produção dos agregados miúdos e graúdos destinados à produção de concretos de cimento Portland. A seguir, são apresentados os resultados obtidos a partir dos estudos de dosagem realizados. 


\subsection{Estudo de dosagem}

Ao todo foram estudados 11 traços, sendo estes divididos em dois grupos (G1 e G2). O primeiro grupo foi composto por traços com diferentes porcentagens, em volume, de PET em substituição, tanto do agregado miúdo, quanto do graúdo. Neste grupo também foi estudado um traço, denominado "padrão", o qual não continha PET. O segundo grupo foi composto por traços os quais não levavam resíduos de PET em sua composição. A seguir são apresentados os traços utilizados, tanto em termos de volume, como em massa.

Quadro 3. Traço em massa e em volume dos concretos dosados com resíduo de PET -G1

\begin{tabular}{|c|c|c|c|c|c|c|}
\hline \multirow[t]{2}{*}{ Materiais } & \multicolumn{2}{|c|}{ Traço 1} & \multicolumn{2}{|c|}{ Traço $2-2,5 \%$} & \multicolumn{2}{|c|}{ Traço $3-5,5 \%$} \\
\hline & $\mathrm{kg}$ & Volume (I) & $\mathrm{kg}$ & Volume (I) & $\mathrm{kg}$ & Volume (I) \\
\hline Cimento & 357 & 119 & 382 & 125 & 408 & 133 \\
\hline Areia 1-quartzo & 233 & 88 & 225 & 85 & 213 & 80 \\
\hline Areia 2 - britada & 550 & 206 & 530 & 198 & 503 & 188 \\
\hline Brita \#1 & 1090 & 407 & 1050 & 392 & 997 & 372 \\
\hline PET granulado & 0 & 0 & 22 & 17 & 48 & 36 \\
\hline Água & 175 & 175 & 182 & 182 & 190 & 190 \\
\hline Aditivo $1(0,6 \%)$ & 2,142 & 2,142 & 2,3 & 2,1 & 2,4 & 2,2 \\
\hline Aditivo $2(0,2 \%)$ & 0,714 & 0,714 & 0,8 & 0,7 & 0,8 & 0,7 \\
\hline \multirow[t]{2}{*}{ Ar incorporado } & \multicolumn{2}{|c|}{ nc } & \multicolumn{2}{|c|}{$\mathrm{nc}$} & \multicolumn{2}{|c|}{$\mathrm{nc}$} \\
\hline & 2408 & 1,00 & 2393 & 1,00 & 2361 & 1,00 \\
\hline Slump (cm) & \multicolumn{2}{|c|}{8,5} & \multicolumn{2}{|c|}{9,0} & \multicolumn{2}{|c|}{8,0} \\
\hline a/c corrigido & \multicolumn{2}{|c|}{0,49} & \multicolumn{2}{|c|}{0,48} & 0,47 & \\
\hline
\end{tabular}

Fonte: Dados da Pesquisa

Quadro 4. Traço em massa e em volume dos concretos dosados com resíduo de PET -G1 (continuação)

\begin{tabular}{|c|c|c|c|c|c|c|c|c|}
\hline \multirow[t]{2}{*}{ Materiais } & \multicolumn{2}{|c|}{ Traço 4 - 9,5\% } & \multicolumn{2}{|c|}{ Traço 5 - 15\% } & \multicolumn{2}{|c|}{ Traço 6 - 22\% } & \multicolumn{2}{|c|}{ Traço 7- 36\% } \\
\hline & kg & $\begin{array}{c}\text { Volume } \\
\text { (I) }\end{array}$ & kg & $\begin{array}{c}\text { Volume } \\
\text { (I) }\end{array}$ & kg & $\begin{array}{c}\text { Volume } \\
\text { (I) }\end{array}$ & kg & $\begin{array}{c}\text { Volume } \\
\text { (I) }\end{array}$ \\
\hline Cimento & 438 & 143 & 473 & 155 & 510 & 167 & 555 & 181 \\
\hline Areia 1-quartzo & 200 & 75 & 185 & 70 & 167 & 63 & 145 & 55 \\
\hline Areia 2-britada & 472 & 177 & 437 & 164 & 393 & 147 & 342 & 128 \\
\hline Brita \#1 & 936 & 349 & 867 & 323 & 779 & 291 & 678 & 253 \\
\hline PET granulado & 77 & 57 & 111 & 83 & 150 & 112 & 196 & 146 \\
\hline Água & 198 & 198 & 207 & 207 & 221 & 221 & 236 & 236 \\
\hline Aditivo $1(0,6 \%)$ & 2,6 & 2,4 & 2,8 & 2,6 & 3,1 & 2,8 & 3,3 & 3,1 \\
\hline Aditivo $2(0,2 \%)$ & 0,9 & 0,8 & 0,9 & 0,9 & 1,0 & 0,9 & 1,1 & 1,0 \\
\hline \multirow[t]{2}{*}{ Ar incorporado } & \multicolumn{2}{|c|}{$\mathrm{nc}$} & \multicolumn{2}{|c|}{$\mathrm{nc}$} & \multicolumn{2}{|c|}{$\mathrm{nc}$} & \multicolumn{2}{|r|}{$\mathrm{nc}$} \\
\hline & 2324 & 1,00 & 2283 & 1,00 & 2223 & 1,00 & 2155 & 1,00 \\
\hline Slump (cm) & \multicolumn{2}{|c|}{7,5} & \multicolumn{2}{|c|}{9,5} & \multicolumn{2}{|c|}{9,0} & \multicolumn{2}{|r|}{9,5} \\
\hline a/c corrigido & \multicolumn{2}{|c|}{0,46} & \multicolumn{2}{|c|}{0,45} & \multicolumn{2}{|c|}{0,44} & \multicolumn{2}{|c|}{0,43} \\
\hline
\end{tabular}

Fonte: Dados da Pesquisa

Quadro 5. Traços em massa e em volume dos concretos dosados sem resíduo de PET - G2

\begin{tabular}{|l|c|c|c|c|}
\hline Materiais & Traço 8 & Traço 9 & Traço 10 & Traço 11 \\
\hline
\end{tabular}




\begin{tabular}{|c|c|c|c|c|c|c|c|c|}
\hline & kg & $\begin{array}{c}\text { Volume } \\
\text { (I) }\end{array}$ & kg & Volume (I) & $\mathrm{kg}$ & $\begin{array}{c}\text { Volume } \\
\text { (I) }\end{array}$ & kg & $\begin{array}{c}\text { Volume } \\
\text { (I) }\end{array}$ \\
\hline Cimento & 439 & 146 & 364 & 121 & 312 & 104 & 272 & 90 \\
\hline Areia 1-quartzo & 198 & 74 & 218 & 82 & 234 & 88 & 245 & 92 \\
\hline Areia 2-britada & 461 & 173 & 510 & 191 & 546 & 204 & 571 & 214 \\
\hline Brita \#1 & 1098 & 410 & 1092 & 407 & 1092 & 407 & 1088 & 406 \\
\hline Resíduo de PET & 0 & 0 & 0 & 0 & 0 & 0 & 0 & 0 \\
\hline Água & 198 & 198 & 197 & 197 & 197 & 197 & 196 & 196 \\
\hline Aditivo $1(0,6 \%)$ & 0 & 0 & 0 & 0 & 0 & 0 & 0 & 0 \\
\hline Aditivo $2(0,2 \%)$ & 0 & 0 & 0 & 0 & 0 & 0 & 0 & 0 \\
\hline Ar incorporado & \multicolumn{2}{|c|}{$1,0 \%$} & \multicolumn{2}{|r|}{$1,0 \%$} & \multicolumn{2}{|c|}{$1,0 \%$} & \multicolumn{2}{|c|}{$1,0 \%$} \\
\hline Slump $(\mathrm{cm})$ & \multicolumn{2}{|c|}{10} & \multicolumn{2}{|c|}{9,5} & \multicolumn{2}{|c|}{10} & \multicolumn{2}{|c|}{10} \\
\hline Relação a/c & \multicolumn{2}{|c|}{0,45} & \multicolumn{2}{|c|}{0,54} & \multicolumn{2}{|c|}{0,63} & \multicolumn{2}{|c|}{0,72} \\
\hline
\end{tabular}

Fonte: Dados da Pesquisa

Conforme apresentado no Quadro 3, o Traço 1 é isento de PET, sendo que os demais tiveram a incorporação em proporções que variaram entre 2,5 a $36 \%$ do volume de agregados (Quadros 3 e 4). Durante a dosagem do concreto nos traços estudados, observou-se que, ao se comparar a trabalhabilidade observada nos traços com PET e sem resíduo, que esta apresentouse pior no primeiro caso, refletindo no aspecto do acabamento dos corpos de prova moldados, que passaram a apresentar vazios em excesso. Modro et al (2009), Wilinski et al (2016), Mello et al (2014) comentam este fenômeno. De acordo com os autores, o concreto tende a apresentar redução na sua trabalhabilidade com incremento de PET em substituição ao agregado natural. Segundo Wilinski et al (2016) o incremento de fibras de PET na dosagem do concreto não reduz a sua resistência, porém prejudica, de forma significativa, a sua trabalhabilidade. Deve-se também destacar nos Quadros 3 e 4 a necessidade de enriquecimento dos traços, com consequente aumento do consumo de cimento, no intuito de manutenção da resistência requerida.

No Quadro 5 foram apresentados traços referentes ao grupo 2 (G2), os quais demonstraram variação de consumo de cimento entre 272 e $439 \mathrm{~kg} / \mathrm{m}^{3}$ e relação água cimento (a/c) variando entre 0,72 e 0,45. Neste grupo não foi necessário utilizar aditivo para concreto, por ter sido atingida a consistência necessária sem adição dos mesmos. $\mathrm{O}$ ar incorporado se manteve constante em todos os traços estudados.

Os corpos de prova, produzidos a partir dos traços estudados, foram levados a câmara úmida para período de cura de 7 e 28 dias. Após estes períodos, os corpos de prova foram submetidos a ensaios de compressão, tal como especificado pela ABNT NBR 9781:2013. A seguir são apresentados os resultados obtidos. 


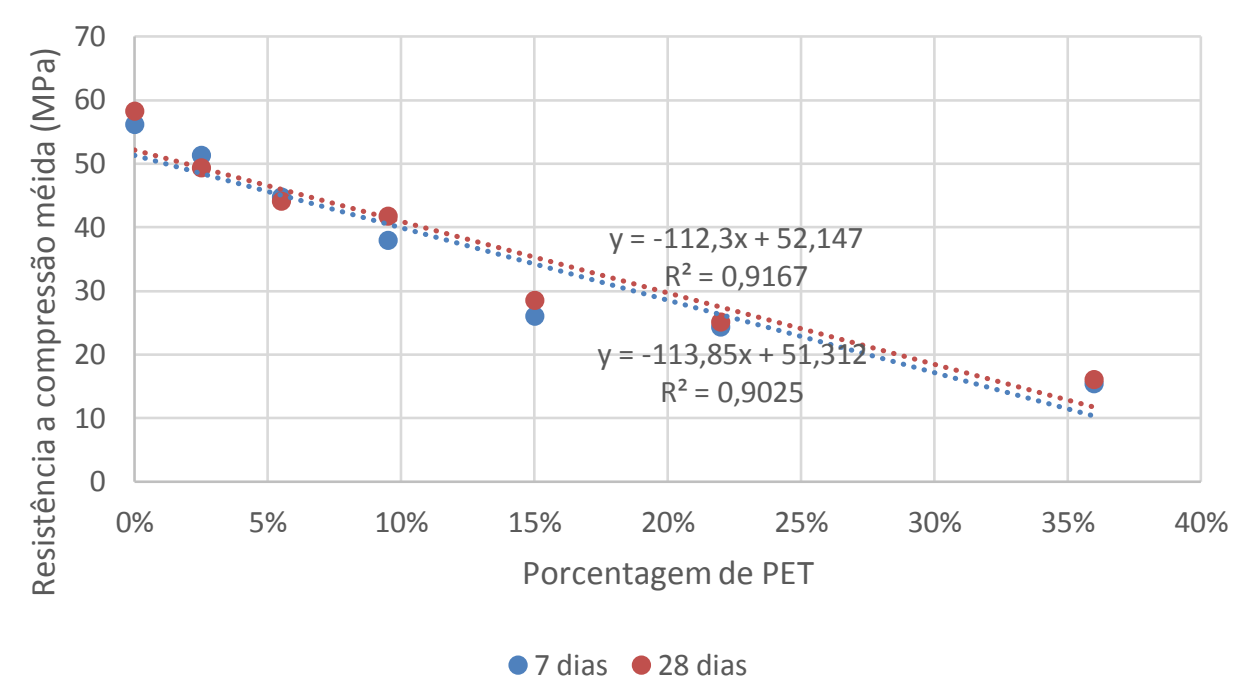

Figura 4. Resistência a compressão média (MPa) dos corpos de prova dosados com PET em diferentes porcentagens - G1. Fonte: Dados da Pesquisa

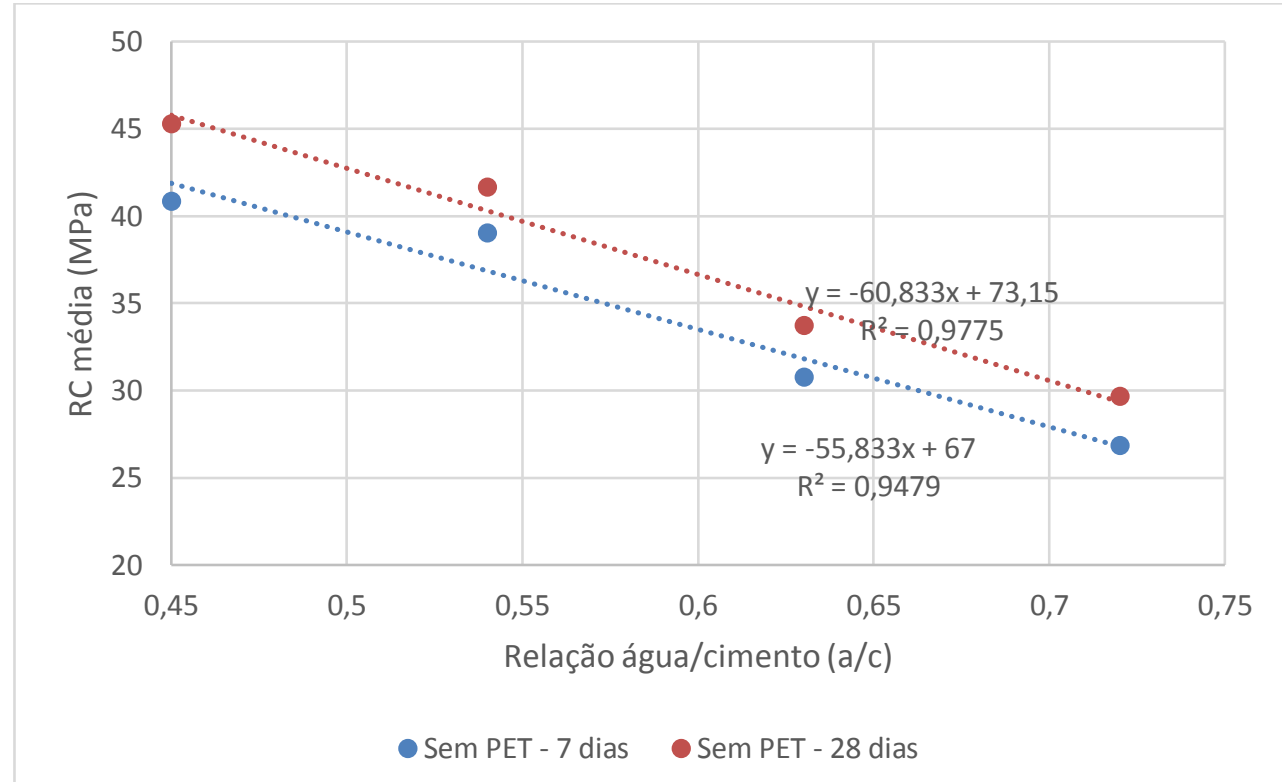

Figura 5. Resistência a compressão média (MPa) dos corpos de prova dosados sem PET em diferentes valores de a/c - G2. Fonte: Dados da Pesquisa

De acordo com a Figura 4 os corpos de prova dosados com o traço 1 padrão (sem PET) foram os que apresentaram maior resistência média a compressão em relação aos demais traços estudados. Nota-se também uma tendência linear de queda de resistência a compressão a medida em que foram incrementadas porcentagens de PET na dosagem em ambos os tempos de cura; tal fato já foi salientado por diversos autores, tais como: Modro et al (2009), Saikia e Brito (2013) e Melo (2014). De acordo com Córdoba et al (2013) grandes concentrações e diâmetros de partículas de PET podem causar acréscimo nos vazios nos corpos de prova e redução da resistência a compressão.

Nota-se por meio da Figura 5 que, para ambos os tempos de cura, há uma tendência de decréscimo da resistência média a compressão dos corpos de prova a medida que se aumenta a relação água/cimento, o que já era de se esperar. As resistências a compressão para tempo de cura 
de 7 dias variaram entre 41 e $27 \mathrm{MPa}$. Ao se considerar tempo de cura de 28 dias, as resistências situaram-se entre 45 e $30 \mathrm{MPa}$.

No intuito de se obter a dosagem necessária de PET, de forma a se alcançar uma resistência de 38,3MPa (fcj), calculada de acordo com a equação 1 ( $\mathrm{fcj}_{28 \text { dias }}=\mathrm{fck}+1,65 \mathrm{sd}$ ), considerando-se 28 dias de tempo de cura e $\mathrm{sd}=2,0 \mathrm{MPa}$; para a dosagem das peças de pavimento intertravado foi utilizada a equação de regressão apresentada na Figura $5(y=-112,3 x+52,147)$. O mesmo procedimento foi utilizado para se determinar a relação água cimento para o traço sem PET. Dessa forma, foi utilizado na dosagem definitiva das peças $12 \%$ de PET (traço 13 ) e relação a/c=0,58 para a dosagem definitiva do bloco sem adição de PET (traço 12). O Quadro 6 apresenta os traços definitivos em termos de volume e massa que foram utilizados para a manufatura das peças de pavimento intertravado.

Quadro 6. Traços definitivos em termos de volume e massa

\begin{tabular}{|c|c|c|c|c|}
\hline \multirow{3}{*}{ Materiais } & \multicolumn{2}{|c|}{ Traço 12} & \multicolumn{2}{|c|}{ Traço 13} \\
\hline & \multicolumn{2}{|c|}{ Sem adição de PET } & \multicolumn{2}{|c|}{ Com adição de $12 \%$ PET } \\
\hline & $\mathrm{kg} / \mathrm{m}^{3}$ & $\mathrm{l} / \mathrm{m}^{3}$ & $\mathrm{~kg} / \mathrm{m}^{3}$ & $\mathrm{l} / \mathrm{m}^{3}$ \\
\hline Cimento & 336 & 111,6 & 441 & 144 \\
\hline Areia 1-Quartzo & 337 & 126,7 & 190 & 72 \\
\hline Areia 2-Britada & 505 & 189,1 & 450 & 168 \\
\hline Brita 1 & 1005 & 375 & 891 & 332 \\
\hline PET em flocos & 0 & 0 & 89 & 66 \\
\hline Água & 197 & 197 & 216 & 216 \\
\hline Aditivo 1 (0,6\%-SMC) & 0 & 0 & 2,6 & 2,4 \\
\hline Aditivo $2(0,2 \%$-SMC) & 0 & 0 & 0,9 & 0,8 \\
\hline Slump $(\mathrm{cm})$ & \multicolumn{2}{|c|}{10,5} & \multicolumn{2}{|c|}{10,0} \\
\hline Relação a/c & \multicolumn{2}{|c|}{0,58} & \multicolumn{2}{|c|}{0,49} \\
\hline Ar Incorporado & \multicolumn{2}{|c|}{1,2} & \multicolumn{2}{|c|}{1,1} \\
\hline
\end{tabular}

Fonte: Dados da Pesquisa

\subsection{Avaliação das peças manufaturadas com os traços definitivos}

A partir da obtenção das peças nos traços apresentados no Quadro 6, ensaios de compressão foram realizados em diferentes tempos de cura (7 e 28 dias). 0 teste de Shapiro-Wilk foi utilizado a fim de verificar se os parâmetros de resistência obtidos pertenciam a uma população normalmente distribuída, o que foi constatado. Dessa forma, as resistências à compressão médias, os desvios padrão, as variâncias e medianas foram calculadas, tal como se pode observar nas Tabelas seguintes. A Figura 6 apresenta o aspecto das peças manufaturadas com os traços definitivos. 


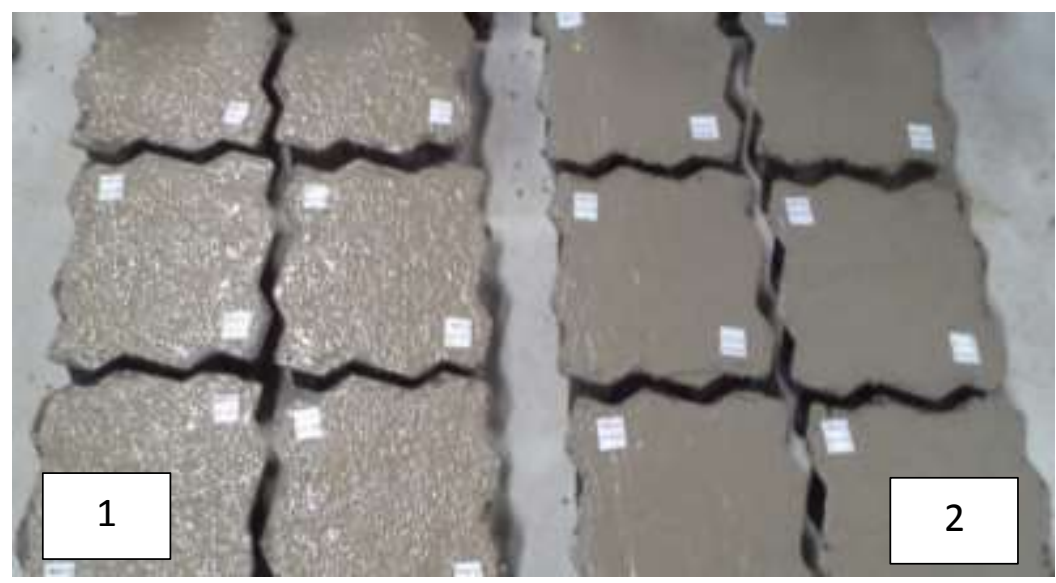

Figura 6. Peças manufaturadas com os traços definitivos- (1) com PET; (2) sem PET.Fonte: Dados da Pesquisa

Tabela 1. Resistências a compressão (MPa) peças manufaturadas sem PET (traço 12)

\begin{tabular}{|c|c|c|c|c|c|c|c|}
\hline \multirow[t]{2}{*}{$\begin{array}{l}\text { Tempo } \\
\text { de cura }\end{array}$} & \multirow[t]{2}{*}{$\begin{array}{c}\text { RC } \\
\text { máx. } \\
\text { (MPa) }\end{array}$} & \multirow[t]{2}{*}{$\begin{array}{l}\mathrm{RC} \\
\text { mín. } \\
(\mathrm{MPa})\end{array}$} & \multirow[t]{2}{*}{$\begin{array}{l}\mathrm{RC}_{\text {Média }} \\
(\mathrm{MPa})\end{array}$} & \multirow[t]{2}{*}{$\begin{array}{c}\text { sd } \\
(\mathrm{MPa})\end{array}$} & \multirow[t]{2}{*}{$\begin{array}{c}\text { Mediana } \\
(\mathrm{MPa})\end{array}$} & \multirow[t]{2}{*}{ Var. } & $\begin{array}{c}\text { Intervalo de } \\
\text { confiança para a } \\
\text { media (95\%) MPa }\end{array}$ \\
\hline & & & & & & & mínimo \\
\hline
\end{tabular}

\begin{tabular}{l|l|l|l|l|l|l|l|l}
\hline $\mathbf{7}$ dias & 38,2 & 35,3 & $\mathbf{3 7 , 0}$ & 0,99 & 37,25 & 0,983 & 35,99 & 38,07 \\
$\mathbf{2 8}$ dias & 43,2 & 38,2 & $\mathbf{4 0 , 2}$ & 1,86 & 39,80 & 3,45 & 38,25 & 42,15 \\
\hline
\end{tabular}

Fonte: Dados da Pesquisa

Tabela 2. Resistências a compressão (MPa) peças manufaturadas com PET (traço 13)

\begin{tabular}{|c|c|c|c|c|c|c|c|c|}
\hline \multirow[t]{2}{*}{$\begin{array}{l}\text { Tempo } \\
\text { de cura }\end{array}$} & \multirow[t]{2}{*}{$\begin{array}{l}\mathrm{RC} \\
\text { máx. } \\
(\mathrm{MPa})\end{array}$} & \multirow[t]{2}{*}{$\begin{array}{c}\mathrm{RC} \\
\text { mím. } \\
(\mathrm{MPa})\end{array}$} & \multirow[t]{2}{*}{$\begin{array}{l}\mathrm{RC}_{\text {Média }} \\
(\mathrm{MPa})\end{array}$} & \multirow[t]{2}{*}{$\begin{array}{c}\mathrm{sd} \\
(\mathrm{MPa})\end{array}$} & \multirow[t]{2}{*}{$\begin{array}{c}\text { Mediana } \\
(\mathrm{MPa})\end{array}$} & \multirow[t]{2}{*}{ Var. } & \multicolumn{2}{|c|}{$\begin{array}{c}\text { Intervalo de confiança } \\
\text { para a media (95\%) } \\
\mathrm{MPa}\end{array}$} \\
\hline & & & & & & & mínimo & máximo \\
\hline 7 dias & 38,5 & 36,7 & 37,7 & 0,69 & 37,85 & 0,47 & 36,94 & 38,38 \\
\hline 28 dias & 43,2 & 39,9 & 41,6 & 1,21 & 41,75 & 1,48 & 40,30 & 42,86 \\
\hline
\end{tabular}

Fonte: Dados da Pesquisa

De acordo com a Tabela 1, nota-se que que a resistência a compressão média dos blocos dosados sem PET aos 7 dias de cura foi de $37 \mathrm{MPa}(\mathrm{sd}=0,99 \mathrm{MPa})$, ao se considerar o tempo de cura referente a 28 dias, tem-se $40,2 \mathrm{MPa}(\mathrm{sd}=1,86)$. Estes valores se mantiveram bem próximos aos apresentados pela Tabela 2, a qual demonstra resistência a compressão média aos 7 e 28 dias de cura equivalentes a $37,7 \mathrm{MPa}(\mathrm{sd}=0,69 \mathrm{MPa})$ e $41,6 \mathrm{MPa}(\mathrm{sd}=1,21 \mathrm{MPa})$ respectivamente. Também pode-se destacar que as resistências a compressão obtidas aos 28 dias de cura, situaram-se próximas ao valor do fcj calculado por meio da equação 1 , o que indica a adequabilidade das regressões lineares apresentadas nas Figuras 4 e 5. Na Figura 7 são comparados os valores médios, as medianas, os valores mínimos e máximos. 


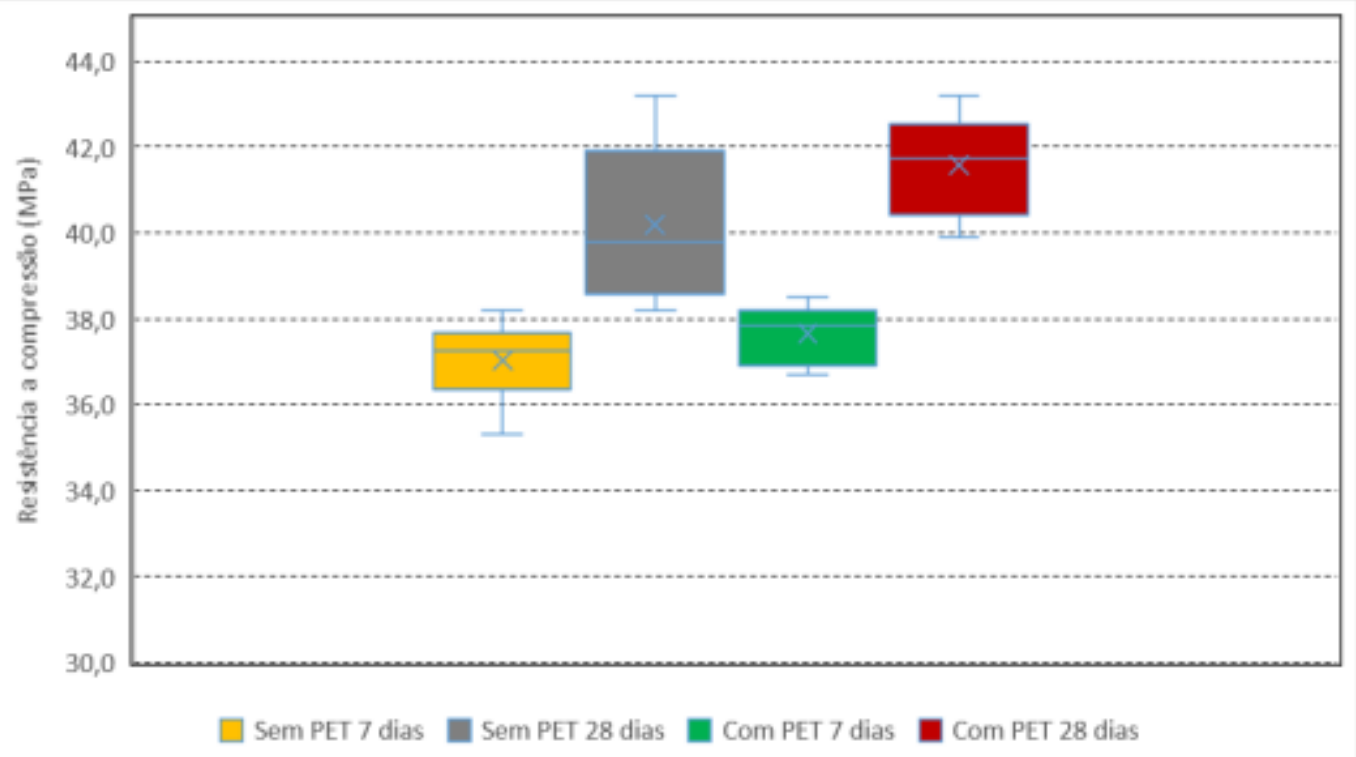

Figura 7. Comparação entre os valores obtidos por meio dos ensaios de resistência a compressão. Fonte: Dados da Pesquisa

A Figura 7 apresenta os valores obtidos nas Tabelas 1 e 2 e demonstra a proximidade dos valores de resistência a compressão obtidos entre os blocos dosados com PET e sem. Dessa forma, no intuito de se avaliar os valores de resistência médias obtidas, a fim de se verificar se há diferença estatística entre estas, foram realizados Testes T de Student, considerando-se nível de confiança de $95 \%$ e as hipóteses seguintes: Ho=não há diferença entre as médias; H1=existência de diferença entre as médias. As Tabelas seguintes apresentam as análises efetuadas.

Tabela 3. Comparação entre RC médias obtidas para traços 12 e 13 (7 dias)

\begin{tabular}{|c|c|c|c|c|}
\hline $\begin{array}{l}\text { Tempo de } \\
\text { cura }\end{array}$ & Traço & $\begin{array}{l}\mathrm{RC}_{\text {Média }} \\
(\mathrm{MPa})\end{array}$ & $\begin{array}{l}\text { Valor de } \\
T_{\text {calculado }}\end{array}$ & $\begin{array}{c}\text { Valor de } \\
T_{\text {tabelado }}\end{array}$ \\
\hline $\begin{array}{l}7 \text { dias } \\
7 \text { dias }\end{array}$ & $\begin{array}{l}12 \text { (sem PET) } \\
13 \text { (com PET) }\end{array}$ & $\begin{array}{c}37 \\
37,7\end{array}$ & 2,73 & 1,812 \\
\hline
\end{tabular}

Fonte: Dados da Pesquisa

Tabela 4. Comparação entre RC médias obtidas para traços 12 e 13 (28 dias)

\begin{tabular}{c|c|c|c|c}
\hline $\begin{array}{c}\text { Tempo de } \\
\text { cura }\end{array}$ & Traço & $\begin{array}{c}\mathrm{RC}_{\text {Média }} \\
(\mathrm{MPa})\end{array}$ & $\begin{array}{c}\text { Valor de } \\
\mathrm{T}_{\text {calculado }}\end{array}$ & $\begin{array}{c}\text { Valor de } \\
T_{\text {tabelado }}\end{array}$ \\
\hline 28 dias & 12 (sem PET) & 40,2 & 3,1 & 1,812 \\
28 dias & 13 (com PET) & 41,6 & & \\
\hline
\end{tabular}

Fonte: Dados da Pesquisa

Por meio dos valores apresentados nas Tabelas 3 e 4 pode-se constatar que as resistências médias obtidas para as peças manufaturadas com PET, foram pouco superiores aos valores obtidos para as peças com traço sem adição de resíduos para ambos os tempos de cura estudados. No intuito de se verificar a diferença entre as resistências médias obtidas para 7 e 28 dias de tempo de cura entre as peças manufaturadas com concreto de mesmo traço, também foram realizados 
Testes T de Student, considerando-se nível de confiança de 95\%. Os resultados são apresentados nas Tabelas seguintes.

Tabela 6. Comparação entre RC médias obtidas para traço 12 (sem PET)

\begin{tabular}{ll|ll}
$\begin{array}{l}\text { Tempo de } \\
\text { cura }\end{array}$ & $\begin{array}{l}\mathrm{RC}_{\text {Média }} \\
(\mathrm{MPa})\end{array}$ & Valor de $\mathrm{T}_{\text {calculado }}$ & $\begin{array}{l}\text { Valor de } \\
\mathrm{T}_{\text {tabelado }}\end{array}$ \\
\hline $\begin{array}{l}7 \text { dias } \\
28 \text { dias }\end{array}$ & $\begin{array}{l}37 \\
40,2\end{array}$ & 3,79 & 1,812 \\
\hline
\end{tabular}

Fonte: Dados da Pesquisa

Tabela 7. Comparação entre RC médias obtidas para traço 13 (com PET)

\begin{tabular}{l|l|l|l}
\hline \multicolumn{1}{l}{$\begin{array}{l}\text { Tempo de } \\
\text { cura }\end{array}$} & $\begin{array}{l}\text { RC Média } \\
(\mathrm{MPa})\end{array}$ & \multicolumn{1}{l}{$\begin{array}{l}\text { Valor de } \\
\text { Tcalculado }\end{array}$} & \multicolumn{1}{l}{$\begin{array}{l}\text { Valor de } \\
T_{\text {tabelado }}\end{array}$} \\
\hline 7 dias & 37,7 & 7,52 & 1,812 \\
28 dias & 41,6 & & \\
\hline
\end{tabular}

Fonte: Dados da Pesquisa

Tabela 8. Relação entre valores de resistência a compressão média entre 7 e 28 dias de cura para ambos os traços

\begin{tabular}{l|l|l|l|l}
\hline $\begin{array}{l}\text { Tempo de } \\
\text { cura }\end{array}$ & Traço & \multicolumn{2}{l}{$\mathrm{RC}_{28} / \mathrm{RC}_{7}$} & \multicolumn{2}{l}{ Traço } & $\mathrm{RC}_{28} / \mathrm{RC}_{7}$ \\
\hline $\begin{array}{l}7 \text { dias } \\
28 \text { dias }\end{array}$ & 13 (com PET) & 1,10 & 12 (sem PET) & 1,06 \\
\hline
\end{tabular}

Fonte: Dados da Pesquisa

Por meio dos valores demonstrados nas Tabelas 6 e 7 pode-se constatar que as resistências médias a compressão, considerando-se os tempos de cura de 7 e 28 dias, diferem entre si estatisticamente. De acordo com a Tabela 8 nota-se que o ganho de resistência ocorrido entre $7 \mathrm{e}$ 28 dias foi de $10 \%$ e $6 \%$ para blocos manufaturados com traço 13 e 12 respectivamente, indicando baixo ganho de resistência no tempo. Deve-se ressaltar que isto ocorre em função do cimento utilizado na manufatura dos concretos utilizados corresponder ao do tipo ARI - Alta Resistência Inicial. Concretos dosados com este tipo de cimento mobilizam valores elevados de resistência compressão nos primeiros 3 dias de tempo de cura.

Também foram conduzidos ensaios de absorção de água nas peças manufaturadas nos traços em estudos considerando-se tempo de cura de 28 dias. Os valores obtidos são apresentados na Tabela 9. Com o objetivo de se verificar a diferença entre as médias obtidas, também foi realizado Teste T de Student considerando-se nível de confiança de 95\% e as hipóteses seguintes:

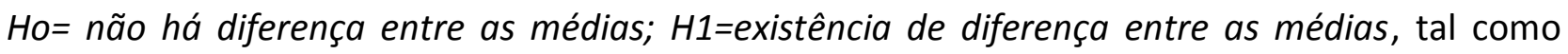
apresentado na Tabela 10.

Tabela 9. Valores de absorção de água obtidos para os traços 12 e 13 (idade 28 dias)

\begin{tabular}{c|c|c|c|c}
\hline \multirow{2}{*}{ Número do CP } & \multicolumn{2}{|c|}{ Traço 13-com PET } & \multicolumn{2}{c}{ Traço 12-sem PET } \\
\cline { 2 - 5 } & Obtido (\%) & Média (\%) & Obtido (\%) & Média (\%) \\
\hline 1 & 5,0 & 5,0 & 4,7 & 4,6 \\
2 & 5,2 & & 4,7 & \\
\cline { 2 - 4 } & & &
\end{tabular}




\begin{tabular}{c|llll}
3 & 4,9 & & 4,3 & \\
\hline Fonte: Dados da Pesquisa & &
\end{tabular}

Tabela 10. Comparação entre valores de absorção média obtidas para traços 12 e 13 (idade 28 dias)

$\begin{array}{ccc}\text { Traço Absorção média } & \text { Valor de } \mathrm{T}_{\text {calculado }} & \text { Valor de } \\ (\%) & & T_{\text {tabelado }}\end{array}$

\begin{tabular}{l|l|l|l}
\hline Traço 13 (28 dias) & 5,0 & 4,41 & 2,13 \\
Traço 12 (28 dias) & 4,6 & & \\
\hline
\end{tabular}

Fonte: Dados da Pesquisa

De acordo com os valores apresentados pode-se constatar que as médias de absorção de água diferem estatisticamente entre si entre as peças manufaturadas nos traços 12 e 13. Também se observa que as peças manufaturadas em concreto dosado com PET apresentaram valor de absorção média de $5,0 \%(s d=0,19)$, ou seja, superior ao valor médio determinado para os blocos manufaturados sem adição de resíduo (média=4,6\%, sd=0,23).

Após obtenção dos dados referentes resistência a compressão e absorção de água, as peças manufaturadas com PET tiveram suas características comparadas aos parâmetros exigidos pela ABNT NBR 9781:2013 a fim de se verificar a adequabilidade destas, tal como se observa por meio do Quadro 7. Também foi realizada, com base no traço 13, a estimativa da quantidade de PET que deixou de ser descartado e a quantidade de agregados naturais que deixou de ser extraída da natureza (Quadro 8).

Quadro 7. Avaliação dos resultados obtidos de acordo com a ABNT NBR 9781:2013

\begin{tabular}{|c|c|c|}
\hline Item analisado & $\begin{array}{c}\text { Requisitos } \\
\text { ABNT NBR 9781:2013 }\end{array}$ & $\begin{array}{c}\text { Resultado obtido } \\
\text { Traço 13 }\end{array}$ \\
\hline $\begin{array}{c}\text { Tráfego de pedestres, } \\
\text { veículos leves e veículos } \\
\text { comerciais de linha }\end{array}$ & $\geq 35 \mathrm{MPa}$ & $41,6 \mathrm{MPa}$ \\
\hline Absorção de água & Deve apresentar valor médio & $56 \%$ \\
\hline
\end{tabular}

Fonte: Dados da Pesquisa

Quadro 8. Quantidades de materiais preservados no meio ambiente

\begin{tabular}{|c|c|c|c|}
\hline Material natural & $\mathrm{kg} / \mathrm{m}^{3}$ & $\mathrm{~kg} / \mathrm{m}^{2}$ & $\mathrm{~kg} / \mathrm{peça}$ \\
\hline Areia natural & 147 & 15,29 & 0,382 \\
\hline Areia artificial & 55 & 36,27 & 0,907 \\
\hline Brita 1 & 114 & 71,83 & 1,796 \\
\hline \multicolumn{4}{|c|}{ Quantidade de resíduo de PET reciclado } \\
\hline Resíduo & $\mathrm{kg} / \mathrm{m}^{3}$ & $\mathrm{~kg} / \mathrm{m}^{2 *}$ & $\mathrm{~kg} / \mathrm{peça}$ \\
\hline PET & 89 & 7,11 & 0,178 \\
\hline
\end{tabular}

Fonte: Dados da Pesquisa

$* 1 \mathrm{~m}^{2}=40$ peças 
Por meio do Quadro 7 pode-se notar que a peça de pavimento intertravado manufaturada com resíduo de PET (traço 13) apresentou resistência a compressão e absorção de água satisfatórios em relação ao exigido pela ABNT NBR 9781:2013. Por meio do Quadro 8 constata-se que cada bloco utiliza uma massa $0,178 \mathrm{~kg}$ de resíduos de $\mathrm{PET}$, o que equivale a um pouco mais de $89 \mathrm{~kg}$ por metro cúbico de concreto, ou $7,11 \mathrm{~kg}$ por metro quadrado de pavimento executado. Dessa forma, pode-se observar que, além da redução da necessidade de utilização de agregados naturais, as peças também retiram quantidades significativas de resíduos, proporcionando uma destinação alternativa a estes.

Para a elaboração da estimativa do custo de produção das peças com e sem inclusão de PET (traços 12 e 13) foram considerados alguns fatores relevantes a manufatura destes, tais como: i) os valores dos insumos restringiram-se à cidade de São Paulo; ii) os custos referentes à mão de obra não foram considerados por não terem relevância para este estudo, uma vez que, entendese que a simples substituição de agregados não impactaria nos custos da mão de obra; iii) o valor do resíduo de PET foi obtido na usina que cedeu o material para a pesquisa; iv) para os demais insumos, consultou-se tabela SINAP, por ser esta considerada uma referência para obtenção de preços na indústria da construção civil; v) o período base para levantamento dos preços foi o ano de 2015; vi) os preços considerados independem do valor de frete. No Quadro 9 são relacionados os materiais e seus preços unitários.

Quadro 9. Estimativa de custo para a produção dos blocos

\begin{tabular}{|c|c|c|}
\hline Item & Traço 13 - com PET & Traço 12 - sem PET \\
\hline Custo total por $\mathrm{m}^{3}$ de concreto & $\mathrm{R} \$ 413,6$ & $\mathrm{R} \$ 203,30$ \\
\hline Custo total por $\mathrm{m}^{2}$ de bloco produzido & $\mathrm{R} \$ 33,4$ & $\mathrm{R} \$ 16,4$ \\
\hline Custo por unidade de bloco produzido & $\mathrm{R} \$ 0,83$ & $\mathrm{R} \$ 0,41$ \\
\hline
\end{tabular}

Fonte: Dados da Pesquisa

De acordo com o Quadro 9, verificou-se que o custo de produção das peças manufaturadas com resídios PET demonstrou-se superior ao do concreto sem PET, isto ocorreu devido ao elevado preço do resíduo de PET e do alto consumo necesário de cimento.

\section{CONCLUSÕES}

De acordo com os resultados obtidos nesta pesquisa pode-se constatar que há uma redução na resistência a compressão do concreto ao se comparar os corpos de prova dosados com e sem PET. Tal fato já foi observado por autores tais como Modro et al (2009), Wilinski et al (2016), Mello et al (2014). Segundo Modro et al (2009) e Saikia e Brito (2013) esta redução da resistência está associada aos seguintes fatores: a menor interação entre o polímero e a matriz cimentícia; pela porosidade residual gerada e; a menor resistência mecânica dos resíduos em relação aos agregados naturais.

As regressões lineares apresentadas nas Figuras 4 e 5 apresentaram-se satisfatórias considerando-se tempo de cura de 28 dias, uma vez que os valores de resistência a compressão 
obtidos por meio dos ensaios dos blocos manufaturados com os traços definitivos (12 e 13) conduziram a valores próximos a 38,3MPa.

As peças manufaturadas com resíduos de PET apresentaram resistências a compressão próximas às obtidas para as peças manufaturada sem adição de resíduo, sendo estas satisfatórios em relação as exigências da ABNT NBR 9781:2013 (RC $\geq 35 \mathrm{MPa})$. Em relação a absorção de água, as peças manufaturadas com resíduos de PET apresentaram valores superiores àqueles observados para as peças sem resíduos. Tal fato pode ter sido influenciado pela presença das partículas de PET presente nas peças manufaturadas com traço 13. Segundo Córdoba et al (2013) concentrações e dimensões maiores deste polímero no concreto podem causar a presença de espaços vazios, ocasionando maiores valores de absorção de água. No entanto, o valor médio de absorção de água obtido encontra-se dentro do recomendado pela ABNT NBR 9781:2013. Dessa forma, pode-se concluir que as peças manufaturadas no traço estudado apresentam viabilidade técnica de utilização em obras de pavimentação, nas condições apresentadas na norma.

No entanto, as peças manufaturadas com resíduos de PET demonstraram custos de manufatura superiores as das peças sem adição de resíduo considerando-se os traços definitivos estudados. Esta situação foi influenciada pelo elevado preço médio do resíduo de PET comercializado pela recicladora e pelo elevado consumo de cimento.

Entretanto, apesar das peças manufaturadas com PET, apresentarem custo mais elevado, deve-se destacar que estas possuem vantagens ambientais significativas em comparação às peças tradicionais; consistindo em uma alternativa para destinação deste tipo de resíduo e na redução da necessidade de extração de agregados em depósitos naturais.

Dessa forma, os resultados obtidos nesta pesquisa ressaltam a idéia que a inovação tecnológica se mostra uma interessante alternativa para a mitigação dos impactos ambientais causados pelos resíduos sólidos gerados pelo setor da construção civil. A prática de incorporação de resíduos sólidos aos processos de fabrição de materiais de construção civil é ressaltado por autores como Safiuddin et al, (2010) Pappu et al (2007), Paschoalin Filho et al (2016), Fioriti et al (2010), Duarte (2013), Modro et al (2009). Na visão destes autores, esta prática além de garantir a correta destinação do resíduo, ainda proporciona a mitigação dos impactos ambientais causados pelo setor.

\section{REFERÊNCIAS}

Akçaözoğlu, S.; Atiş, C. D.; Akçaözoğlu, K. (2010) An investigation on the use of shredded waste PET bottles as aggregate in lightweight concrete. Waste Management, v.30, n.2, p.285-290.

Alfahdawi, I.; Osman, S.A.; Al-Hadith, R.H.A. (2016) Utilizing waste plastic polypropylene and polyethylene terephthalate as an alternative aggregate do produce lightweight concrete: a review. Journal of Engineering Science and Technology, v.11, n.8, p.1165-1173.

Associação Brasileira de Normas Técnicas. ABNT NBR 9781: Peças de concreto para pavimentação Especificação e métodos de ensaio. Rio de Janeiro: ABNT, 2013. 21p. 
Associação Brasileira de Normas Técnicas. ABNT NBR NM 26: Agregados - Amostragem. Rio de Janeiro: ABNT, 2009. 10p.

Associação Brasileira de Normas Técnicas. ABNT NBR 7211: Agregados para concreto-Especificação. Rio de Janeiro: ABNT, 2009. 9p.

Associação Brasileira de Normas Técnicas. ABNT NBR 9479: Argamassa e concreto - Câmaras úmidas e tanques para cura de corpos-de-prova. Rio de Janeiro: ABNT, 2006. 2p.

Associação Brasileira de Normas Técnicas. ABNT NBR NM 248: Agregados - Determinação da composição granulométrica. Rio de Janeiro: ABNT, 2003. 6p.

Associação Brasileira de Normas Técnicas. ABNT NBR 5741: Extração e preparação de amostra de cimento. Rio de Janeiro: ABNT, 1993. 3p.

Associação Brasileira de Normas Técnicas. ABNT NBR 5733: Cimento Portland de alta resistência inicial. Rio de Janeiro: ABNT, 1991. 5p.

Córdoba, L.A.; Martinez-Barrera, G.; Diaz, C.B.; Nuñes, F.U.; Yañes A.L. (2013) Effects on mechanical properties of recycled PET in cement-based composites. International Journal of Polymer Science, v. 2013, artigo ID763276, 6 p. http://dx.doi.org/10.1155/2013/763276.

Duarte, E.B.L. Resistência a compressão de argamassa composta por resíduo de construção e demolição e Politereftalato de etileno (PET) em flocos. (2013) Dissertação (Mestrado em Gestão Ambiental e Sustentabilidade). Programa de Mestrado em Gestão Ambiental e Sustentabilidade. Universidade Nove de Julho, $170 \mathrm{p}$.

Fioriti, C.F.; Ino, A.; Akasaki, J.L. (2010) Análise experimental de blocos de concreto com adição de resíduos do processo de recauchutagem de pneus. Acta Scietiarum. Technology, v.32, n.3, p.237244.

Fioriti, C.F.; Ino, A.; Akasaki, J.L. (2007) Avaliação de blocos de concreto para pavimentação intertravada com adição de resíduos de borracha provenientes da recauchutagem de pneus. Ambiente Construído, v.7, n.4, p.43-54.

Gencel, O.; Ozel, C.; Koksal, F.; Erdogmus, E.; Martínez-Barrera, G.; Brostow, W. (2012)Properties of concrete paving blocks made with waste marble. Journal of Cleaner Production, v.21, n.1, p. 62-70.

Gorninski, J.P.; Tonet, K.G. (2016) Avaliação das propriedades mecânicas e da flamabilidade de concretos poliméricos produzidos com resina PET e retardante de chamas reciclados. Ambiente Construído, v.16, n.2, p. 69-88.

Magalhães, M.S.; Fernades, M.S.V. Bending Behavior of Recycled PET Fiber Reinforced Cement-Base Composite. (2015) International Journal of Engineering and Technology, v.7, n. 4, p. 282-286.

Marzouk, O.Y.; Dheilly, R.M.; Queneudec, M. (2007) Valorization of post-consumer waste plastic in cementitious concrete composites. Waste Management, v.27, p.310-318.

Mello, E.; Ribellato, C.; Mohamedelhassan, E. (2014) Improving concrete properties with fibers addition. International Journal of Civil, Environmental, Structural, Construction and Architectural Engineering, v.8, n.3, p.249-254. 
Modro, N.L.R.; Modro, N.R.; Oliveira, A.P.N. (2009) Avaliação de Concreto de Cimento Portland Contendo Resíduos de PET. Revista Matéria, v.14, n.1, p.725-736.

Moreira, A. B. S.; Macedo, A. N.; Souza, P. S. L. (2012) Masonry concrete block strength compound with sawdust according to residue treatment. Acta Scientarum Technology, v.34, n.3, p.269-276.

Navya, G.; Rao, J.V. Experimental investigation on properties concrete paver block with inclusion of natural fibers. (2014) International Journal of Engineering Research and Applications, v.4, n.8, p.3438.

Ochi, T.; Okubo, S.; Fukui, K. (2007) Development of Recycled PET Fiber and its Application a ConcreteReinforcing Fiber. Cement and Concrete Composites, v.29, p. 448-455.

Pappu, A.; Saxena, M.; Asolekar, S. R. (2007) Solid wastes generation in India and their recycling potential in building materials. Building and Environment, v.42, n.6, p.2311-2320.

Paschoalin Filho, J.A.; Storopoli, J.H.; Dias, A.J.G. Evaluation of Compressive Strength and Water Absorption of Soil-Cement Bricks Manufactured With Addition of PET Wastes. (2016) Acta Scientiarum Technology, v.38, n.2, p.163-171.

Pires, G.W.M.O. Avaliação técnica e econômica de blocos para piso intertravado manufaturados com concreto dosado com resíduos de PET (Politereftalato de etileno) como alternativa sustentável na construção civil. (2015) Dissertação (Mestrado). Programa de Mestrado em Gestão Ambiental e Sustentabilidade. Universidade Nove de Julho, 112 p, 2015.

Ramadevi, K.; Manju, R. Experimental Investigation on the properties of concrete with plastic PET (bottle) fibers as fine aggregates. (2012) International Journal of Emerging Technology and Advanced Engineering, v.2, n.6, p.42-46.

Rodrigues, P. P. F. Parâmetros de dosagem do concreto. Associação Brasileira de Cimento Portland (ABCP), São Paulo, 1995.

Saikia, N.; Brito, J. (2014) Mechanical properties and abrasion behavior of concrete containing shredded PET bottle waste as a partial substitution of natural aggregate. Construction and Building Materials, n.52, p.236-244.

Safiuddin, M.; Jumaat, M. Z.; Salam, M. A.; Islam, M. S.; Hashim, R. (2010) Utilization of solid wastes in construction materials. International Journal of Physical Sciences, v.5, n.13, 1952-1963.

Saikia, N.; Brito, J. (2013) Waste Polyethylene Therefthalate as an Aggregate in Concrete. Materials Research, v.16, n.2, p.341-350.

Suliman, M.; Hapomiuk, J.; Formela, K. (2016) Utilization of Recycled Polyethylene Terephthalate (PET) in Engineering Materials: A Review. International Journal of Environmental Science and Development, v.7, n.2, p. 100-108.

Thanaya, I.N.A. (2009) Asphalt-Bound masonry block incorporating construction demolition waste. ITS International Journal of Civil Engineering, v.29, n.1, p. 20-27. 
Wilinski, D.; Lukouwski, P.; Rokicki, G. (2016) Application of fibers from recycled PET bottles for concrete reinforcement. Journal of Building Chemistry, n.1, p. 1-9. 